\title{
Free and bound MCPD and glycidyl esters in smoked and thermally treated fishery products of the German market
}

\author{
Ute Ostermeyer $^{1} \cdot$ Sybille Merkle $^{1} \cdot$ Horst Karl $^{1} \cdot$ Jan Fritsche ${ }^{1}$ \\ Received: 10 February 2021 / Revised: 25 March 2021 / Accepted: 3 April 2021 / Published online: 16 April 2021 \\ (c) The Author(s) 2021
}

\begin{abstract}
To provide a comprehensive overview of the amounts of unesterified and bound 2- and 3-monochloropropanediol (MCPD) and glycidyl esters (G-E) in processed fishery products sold in Germany, an analysis of various frequently consumed products was conducted. In total, 258 commercial samples of breaded and pre-fried fishery products (e.g., frozen fish fingers), fried fish products (e.g., products in marinade), canned fish, smoked fish and some smoked spice preparations were examined. In addition, the effect of different kitchen preparation methods (e.g., baking, frying and roasting) on the MCPD and G-E amounts of fish fingers was studied. The mentioned process contaminants, MCPD and G-E, were quantifiable in the majority of the samples. Although pre-fried and fried fishery products predominantly contained MCPD esters (MCPD-E), mainly free MCPD was found in smoked fish. Compared with other types of smoke generation, hot smoked fish prepared in traditional Altona smoking kilns contained, on average, the highest 3-MCPD contents (range: 12-246 $\mu \mathrm{g} / \mathrm{kg}$ ). The amounts of bound MCPD in the fried fish products (range for 3-MCPD-E: $<$ LOQ- $808 \mu \mathrm{g} / \mathrm{kg}$ ) were not significantly different from the amounts in the investigated pre-fried fish samples (range for 3-MCPD-E: $<$ LOQ-792 $\mu \mathrm{g} / \mathrm{kg}$ ). However, they differ significantly from the amounts in unfried products $(<\mathrm{LOQ})$. After preparation in the kitchen, the contents in the ready-to-eat fish fingers depend primarily on the initial contaminant amounts of the frozen product and/or the frying oil, respectively.
\end{abstract}

Keywords MCPD $\cdot$ MCPD ester $\cdot$ Glycidyl ester $\cdot$ Fishery products $\cdot$ Market basket $\cdot$ Domestic preparation

\section{Introduction}

The chloropropanols 2- and 3-monochloropropanediol (2and 3-MCPD) are food process contaminants that might be formed by heating fat-containing foods in the presence of chloride-donating compounds. Furthermore, they can be formed during smoking [1] as well as during the hydrolysis of food with hydrochloric acid at elevated temperatures, as used in the production of soy sauce and vegetable protein hydrolysate [2]. The contaminants 2- and 3-MCPD are present in food both in the unesterified form and as monoand di-esters of fatty acids [3]. Glycidyl esters (G-E) are contaminants that often coexist with 2- and 3-MCPD esters (MCPD-E) [3].

Ute Ostermeyer

ute.ostermeyer@mri.bund.de

1 Department of Safety and Quality of Milk and Fish Products, Max Rubner-Institut, Federal Research Institute of Nutrition and Food, Hermann-Weigmann-Straße 1, 24103 Kiel, Germany
Unesterified (free) 3-MCPD is a non-genotoxic compound that has been classified by the International Agency for Research on Cancer (IARC) as a possible human carcinogen (group 2B) [4]. 3-MCPD-E are effectively enzymatically hydrolysed in the gastrointestinal tract, so the esters should be toxicologically evaluated as free $3-\operatorname{MCPD}[3,5]$. For 3-MCPD, a tolerable daily intake (TDI) of $2 \mu \mathrm{g} / \mathrm{kg}$ body weight has been established by the European Food Safety Authority (EFSA) [6]. Based on the same study, the Joint FAO/WHO Expert Committee on Food Additives defined a different provisional maximum tolerable intake (PMTDI) of $4 \mu \mathrm{g} / \mathrm{kg} /$ day [7]. Presently, 2-MCPD is not yet classified with regards to carcinogenicity due to insufficient toxicological data $[8,9]$.

Owing to the high reactivity of glycidol (2,3-epoxy1-propanol), only G-E are found in food [3]. G-E are widely hydrolysed during digestion, releasing glycidol [10]. Free glycidol has been classified by IARC as a genotoxic compound, which is probably carcinogenic to humans (group 2A) [11]. For glycidol, instead of a TDI value, the 
ALARA (as low as reasonably achievable) principle must be respected [3].

The European Commission has set a regulatory limit of $20 \mu \mathrm{g} / \mathrm{kg}$ for 3-MCPD in hydrolysed vegetable protein and soy sauce, which refers to liquid products containing $40 \%$ dry matter [12]. In the year 2018, maximum levels for $\mathrm{G}-\mathrm{E}$ in vegetable oils and fats $(1000 \mu \mathrm{g} / \mathrm{kg})$, infant formula, follow-up formula and foods for special medical purposes for infants and young children $(6 \mu \mathrm{g} / \mathrm{kg}$ in liquids or $50 \mu \mathrm{g} /$ $\mathrm{kg}$ in powders) were established [13]. For these products, maximum levels for the sum of free and bound 3-MCPD were recently specified in the Commission Regulation (EU) 2020/1322 [14]. However, no limits have been published for MCPD-E in other foodstuffs. In principle; however, food containing a contaminant in an amount that is hazardous to health may not be marketed [15].

MCPD-E and G-E can be formed in considerable quantities during the refining process of edible fats and oils, mainly during deodorisation [16]. Their contents have already been determined in a broad variety of refined oils and foods containing these oils. Furthermore, free and bound 3-MCPD have already been detected in various types of heated food, including coffee, bakery products, infant formula, smoked, grilled and fried meat, fish, cheese and vegetable products [e.g., 5, 17-22]. In 2016, the EFSA published data on the occurrence of MCPD, MCPD-E and G-E in food from 23 European member states collected between 2009 and 2015 [8]. However, only limited data of these contaminants in fish and fish products have been published [8, 22-24]. The EFSA has called for more data on free and bound MCPD and G-E in foods, including fishery products [25].

In Germany, preserves and marinades as well as frozen fish are the best-selling fish products (28\% market share each) in 2019 [26]. In the frozen food sector, there is an increasing demand for convenience products, such as breaded and pre-fried frozen fish products. In 2019, the total production weight of frozen fish products in Germany amounted to 228,926 tons [26]. This group also includes fish fingers and other breaded fish products.

According to the German "Guidelines for Fish, Crustaceans and Molluscs and Products derived therefrom "(GFCM), fish fingers are defined as "breaded fish portions of elongated shape, usually pre-fried, from blocks of practically boneless fish fillets, whereby the weight of each breaded fish finger is usually $30 \mathrm{~g}$ " [27].

For their production, frozen fish portions (of around $20 \mathrm{~g}$ ) are first breaded wet and then dry [28]. Fish fingers are mostly pre-fried at temperatures between 160 and $200{ }^{\circ} \mathrm{C}$, whereby the raw fish core remains frozen. Frying times of up to one minute are sufficient [29]. For pre-frying, rapeseed oil, sunflower oil or a mixture of both is often used. Before consumption, the fish fingers must be finally prepared by a second frying step or otherwise heating [29,33].

The group of fish preserves and marinades includes pickled fried fish products in vinegar, sauces, dips or oil. In Germany, mainly herring, and to a lesser extent mackerel or eels, are used as raw materials [29].

For their production, fish fillets or whole gutted fish are lightly salted, breaded and then deep-fried in hot vegetable oil at temperatures between 140 and $200{ }^{\circ} \mathrm{C}$ for approximately $3-15 \min [29,39]$. The cooled fried fish is then placed in an aqueous marinade or sauce. To extend their shelf life, fried fish products can be pasteurised at $95-98^{\circ} \mathrm{C}$ for approximately $45 \mathrm{~min}$ [29].

In 2019 , approximately $12 \%$ of fish products consumed in Germany are smoked, corresponding to $22,873 \mathrm{t}$ [26]. The production is mainly done in small and medium-sized smokehouses.

According to GFCM, smoked fish are products of various prepared fresh fish, frozen fish or fish parts, salted or presalted fish or fish parts that are prepared by the treatment with freshly developed smoke [27]. Hot-smoked fish is produced at a temperature greater than $60{ }^{\circ} \mathrm{C}$ in the fish core, and cold-smoked fish at a temperature less than $30^{\circ} \mathrm{C}$ [27]. The smoking period mainly depends on the type and size of the fish and is usually $1.5-3 \mathrm{~h}$ for hot smoking, whereas cold smoking takes some hours to several days [29]. The cold smoking process is mostly carried out at intervals.

In Germany, various smoking technologies are applied for smoking fish. The traditional smoking in a so-called "Altonaer Ofen" includes drying the fish over an open fire and then smoking them over smouldering wood shavings in the same chamber (direct smoking). The quality of the products mainly depends on the experience of the smokers. In modern smoking kilns, the smoke is added automatically from external smoke generators (indirect smoking) [29]. For smoking fish, mainly smouldering and friction smoke generators are in use. The smouldering smoke generator can be operated with wood shavings or sawdust, with or without the addition of spices, while the friction smoke generator requires the use of square timbers. The pyrolysis temperature is lower for a friction smoke generator $\left(\right.$ at $400{ }^{\circ} \mathrm{C}$ ) than for a smouldering smoke generator $\left(650-700{ }^{\circ} \mathrm{C}\right)$ [29]. Another possibility of generating smoke is the use of wood smoke condensates, also known as liquid smoke. Liquid smoke is rarely used for smoking fish in Germany [29, 30].

Thus, for the production of breaded and pre-fried frozen fish products (e.g., fish fingers), deep-fried and pickled fish, canned and smoked fish, thermal processes, such as (pre-) frying, pasteurising and smoking are important process steps in both industrial and artisanal fish processing. These foods have comparatively high fat and saline contents. Therefore, thermally treated fish products are intrinsically predestined 
to contain increased amounts of MCPD and glycidol as well as their fatty acid esters.

To provide a comprehensive overview of current MCPD, MCPD-E and G-E amounts in commercial products and data for a possible risk assessment of these product groups, a market basket analysis was conducted. Samples of breaded and pre-fried frozen, deep-fried, canned and smoked fish products as well as some smoked spice preparations offered on the German market were examined. In addition, the influence of the domestic cooking of fish fingers was investigated.

\section{Materials and methods}

\section{Samples}

All fishery products, 247 in total, were purchased at different locations in northern Germany between June 2015 and September 2017. The samples were collected from retail or wholesale as well as directly from the manufacturer. The package sizes varied between 100 and $1 \mathrm{~kg}$. On average, approximately $500 \mathrm{~g}$ of a product pooled from several packages with the same batch number was used as the test material. In the case of unpackaged goods several fish were used to yield one sample.

Only the edible part of all samples was homogenised using a blender (Grindomix GM 300, Retsch, Germany). Marinated fish products were separated from the liquid, and then, only the meat content was examined. Canned fish products were analysed without oil. On the other hand, fish products in a sauce are usually completely eaten and have therefore been completely homogenised. In the case of smoked fish, the skin was always removed, except of sprats, as these fish are eaten with skin.

The homogenates were placed into plastic bags with as little air as possible and then stored in a frozen storage chamber at $-24{ }^{\circ} \mathrm{C}$ until analysis.

In addition, eleven spice preparations and three barbecue sauces, all containing smoked ingredients or smoke flavour, were purchased in retail stores in 2019. Only one can or jar containing $40-150 \mathrm{~g}$ of each product served as a sample. Albeit, the sauces were in $250 \mathrm{~mL}$ bottles. The samples were produced by eight different manufacturers.

For the domestic preparation two kinds of commercially available pre-fried fish fingers, containing 65\% Alaska pollack (Gadus chalcogrammus; product 1) or Atlantic salmon (Salmo salar; product 2), and one sample of pre-fried breaded Alaska pollack in the form of sticks, containing $49 \%$ fish (product 3), were prepared in four different ways: oven, pan, mini-fryer and hot-air fryer. Refined sunflower oil was used for frying in the pan. For kitchen frying purpose partially hydrogenated coconut fat as well as high heatable vegetable fat consisting of palm fat and rapeseed oil were used. Raw and prepared fish fingers were homogenised and stored deep-frozen, whereas fresh and used fat/oil samples were stored at room temperature until analysis.

\section{Domestic cooking procedures}

All cooking procedures followed the recommendations of the manufactures.

For baking in an electric oven, the oven was preheated to $200^{\circ} \mathrm{C}$ (air circulation), baking paper was placed on a tray, frozen fish fingers/sticks were put on top and then the tray was placed into the middle of the oven. All three products (in total 19 fish fingers) were baked simultaneously for $15 \mathrm{~min}$, and they were turned once after $10 \mathrm{~min}$.

In a hot-air fryer (capacity $2.6 \mathrm{~L}$ ), one product at a time was heated at $180{ }^{\circ} \mathrm{C}$ for $21 \mathrm{~min}$. After $10 \mathrm{~min}$, all fish fingers/sticks were turned over. This kitchen utensil was used without the addition of frying oil.

For roasting, approximately $120 \mathrm{~g}$ sunflower oil was heated in a pan with a base diameter of $22 \mathrm{~cm}$. The frozen fish fingers were placed into the pan and then roasted at medium temperature for $8 \mathrm{~min}$, turning every $2 \mathrm{~min}$. The temperature measured in the oil was $165-170{ }^{\circ} \mathrm{C}$. The three products were roasted separately in the same way, each in fresh oil. After roasting, the fish fingers dripped on household paper for approximately $30 \mathrm{~s}$.

In addition, frozen fish fingers were deep-fat fried at $180^{\circ} \mathrm{C}$ in a small kitchen fryer for $5 \mathrm{~min}$. Coconut $(1250 \mathrm{~g})$ and vegetable fat $(1000 \mathrm{~g})$ were used as frying fats. The fish fingers were placed in the fryer basket and plunged into the heated oil. During heating, the fryer was kept closed. The three products were fried in the same way, one after the other using the same frying oil. After each frying, approximately $5 \mathrm{~g}$ of frying oil was removed and stored for MCPD-E and $\mathrm{G}-\mathrm{E}$ analysis.

At the end of each preparation, the weight loss of the fish fingers during baking/roasting/frying was determined. Then, all fish fingers of one product were combined and homogenised. The MCPD-E and G-E contents in the pooled homogenates as well as in the fresh and used frying oil samples were analysed.

\section{Gas chromatographic methods}

MCPD, MCPD-E and G-E amounts were determined using the following two methods [24]. The modified SGS "3-in-1 method" (AOCS Official Method Cd 29b-13) was used to quantify the MCPD-E and G-E in the samples. The quantification of free MCPD was performed using the adapted and validated DGF method C-VI 18 (10). In both methods, the contaminants are quantified by using the corresponding isotope-labelled internal standards. Each sample was analysed at least thrice. 
- Determination of free 2- and 3-MCPD

For the determination of free MCPD according to the DGF method C-VI 18 (10) modified for fish products, $10 \mathrm{~g}$ of the homogenised samples was analysed after sample preparation and derivatisation by gas chromatography coupled with mass spectrometry (GC-MS) [24]. The limit of quantification (LOQ) for free 2- and 3-MCPD was $10 \mu \mathrm{g} /$ $\mathrm{kg}$ fish product, and the limit of detection (LOD) for the two compounds was $3 \mu \mathrm{g} / \mathrm{kg}$ fish product.

- Determination of ester bound 2- and 3-MCPD and esterified glycidol

In $0.5 \mathrm{~g}$ of the homogenised fish sample or frying oil, the contents of bound 2- and 3-MCPD and G-E were determined by GC-MS according to the modified AOCS method Cd 29b-13 (SGS “3-in-1 method") [24]. The method is based on an alkaline ester hydrolysis under mild conditions ( $-22{ }^{\circ} \mathrm{C}, 16 \mathrm{~h}$ ). Stopping the ester cleavage reaction by an acidified sodium bromide solution causes a targeted conversion of the glycidol released from $\mathrm{G}-\mathrm{E}$ into 3-mono-bromopropanediol (3-MBPD). Free MCPD and 3-MBPD are derivatised by phenylboronic acid and quantified separately. With this method, the sum of free and bound MCPD is determined if both are simultaneously present.

The reported contents of MCPD-E and G-E in Tables 1, 2, 3 and 5 are expressed as free MCPD and glycidol equivalents, respectively. The limit of quantification (LOQ) for this method was $20 \mu \mathrm{g} / \mathrm{kg}$ for 2- and 3-MCPD-E and G-E in the fish products as well as in frying oils. The LOD for these compounds was $7 \mu \mathrm{g} / \mathrm{kg}$ fish product.

The contents always refer to the edible part of the food. For the calculation of the median and the mean, half of the LOQ value (middle bound) was used for samples with contents below the LOQ. In the case that the contents in all samples of a product group were below the LOQ, then only $<$ LOQ is specified.

For quality assurance, an internal reference material consisting of one-third smoked sprat and two-thirds fish fingers was regularly examined.

\section{Statistical analysis}

For identifying significant differences between the contents of the contaminants in the products an ANOVA followed by post hoc $t$ test according to Tukey and Bonferroni was calculated. A significance level of $\alpha=0.05$ was applied. If the contents of more than ten samples were averaged, the $95 \%$ percentile was calculated.

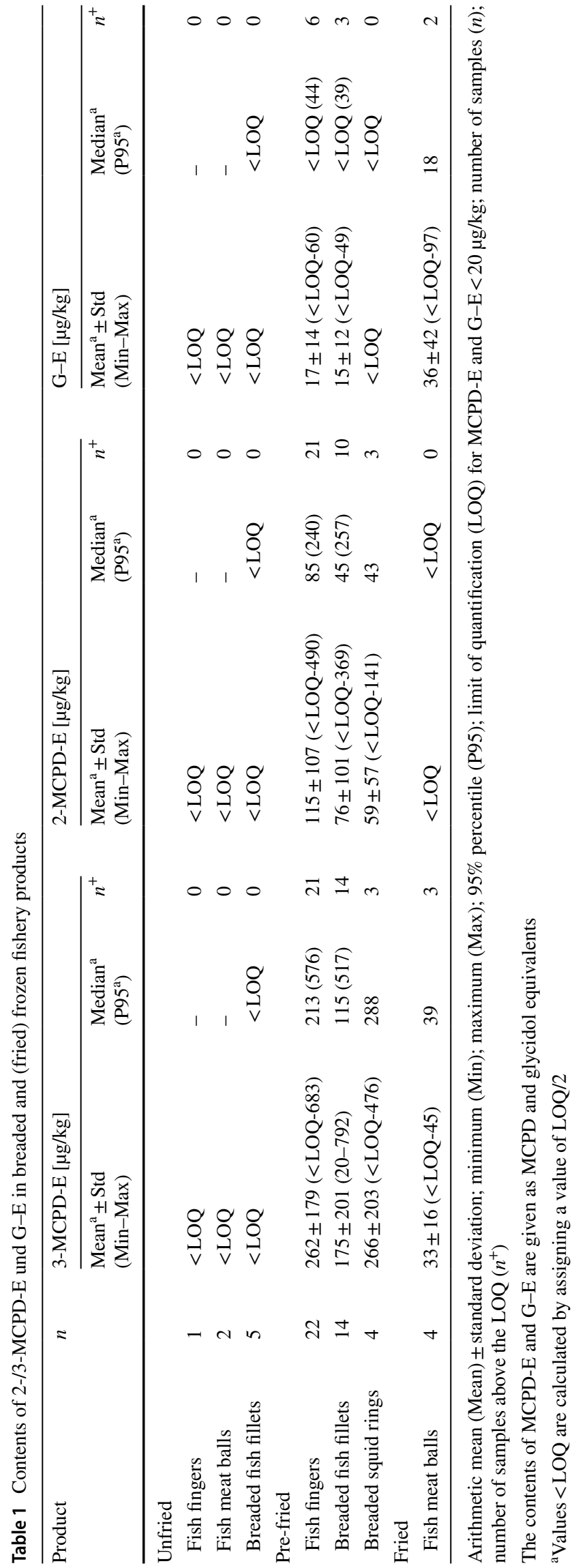




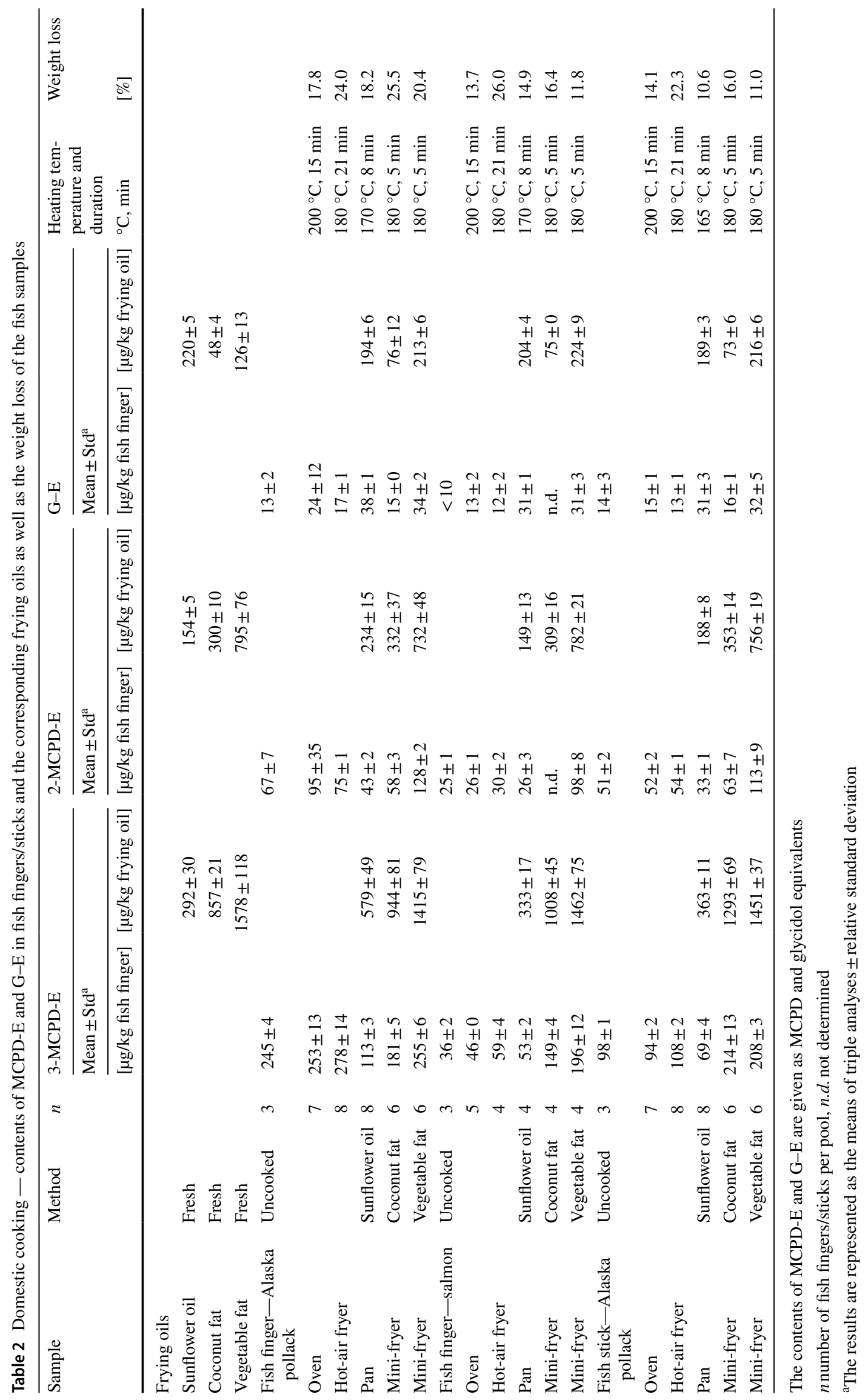




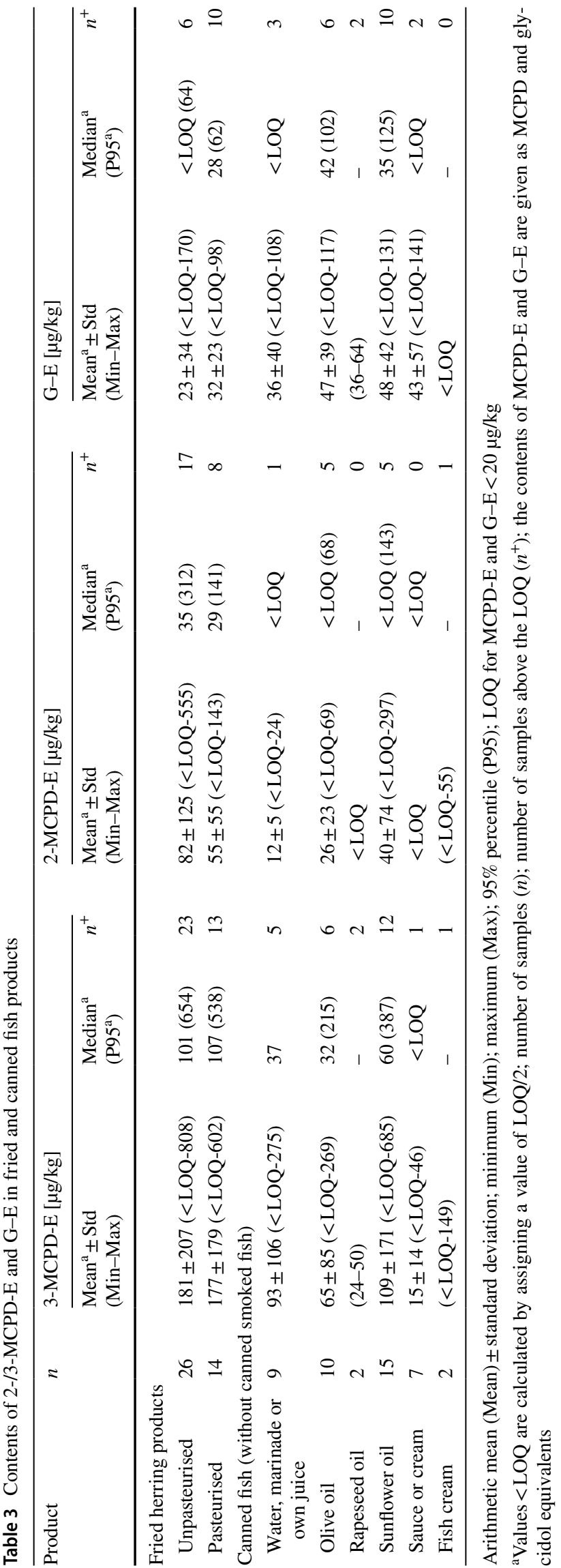

\section{Results and discussion}

\section{Breaded and pre-fried frozen fishery products}

Preliminary studies have shown that the amounts of free MCPD in breaded and pre-fried frozen fish products were below the LOQ [24]. Therefore, free MCPD was not further analysed in this product group. The analysed amounts of 2- and 3-MCPD-E and G-E in the market samples are summarised in Table 1. More information on the individual samples can be found in the supplement Table $\mathrm{S} 1$.

As breaded and pre-fried frozen fish, 21 fish finger samples (fish content $\geq 65 \%$ ) and two fish stick samples (fish content $\leq 50 \%$ ) from twelve different manufacturers were analysed. Only one market sample was offered unfried.

With one exception, in all pre-fried fish fingers/sticks, both 3-MCPD-E and 2-MCPD-E could be quantified and the amounts ranged from $<\mathrm{LOQ}$ to $683 \mu \mathrm{g} / \mathrm{kg}$ and $<\mathrm{LOQ}$ to $490 \mu \mathrm{g} / \mathrm{kg}$ (Table 1). The amounts of 3-MCPD-E were, on average, 2.6 times greater than the amounts of 2-MCPD-E. G-E were mainly not quantifiable in these samples. Only individual products contained up to $60 \mu \mathrm{g} /$ $\mathrm{kg}$.

For an adult with a body weight of $70 \mathrm{~kg}$, the tolerable daily intake is $140 \mu \mathrm{g}$. Even if $150 \mathrm{~g}$ of one of the heaviest contaminated products (approximately $680 \mu \mathrm{g}$ $3-\mathrm{MCPD}-\mathrm{E} / \mathrm{kg}$ ) is consumed, the TDI value will not be exceeded. However, fish fingers are often eaten by children. The 3-MCPD-E amounts of more than half of the tested products $(n=12)$ contained more than $200 \mu \mathrm{g} /$ $\mathrm{kg}$. This has repeatedly led to a significant devaluation in test reports in German consumer magazines such as ÖKOTEST because, in those cases, a child ( $30 \mathrm{~kg}$ ) eating five fish fingers $(150 \mathrm{~g})$ may already consume more than $50 \%$ of the tolerable daily amount $[31,32]$.

In addition to fish fingers/sticks, another 29 breaded frozen fishery products from 12 different manufacturers were examined. The fish or squid content of the products varied between 40 and $68 \%$. Not all of the products were pre-fried.

Nineteen products contained fillets or portions cut from fish blocks. The contents of MCPD-E in these products varied widely (Table 1). 3-MCPD-E was quantifiable in all samples at amounts between 20 and $369 \mu \mathrm{g} / \mathrm{kg}$, except one product which contained a much higher amount of 3-MCPD$\mathrm{E}(792 \mu \mathrm{g} / \mathrm{kg})$. Amounts of 3-MCPD-E were, apart from one product, above the contents of 2-MCPD-E. G-E were below LOQ except one product which contained $49 \mu \mathrm{g} / \mathrm{kg} \mathrm{G}-\mathrm{E}$.

The breaded squid rings had a squid content of $40-50 \%$. The four products studied were pre-fried. 
In the squid products, G-E was not quantifiable $(<$ LOQ). The amounts of 3-MCPD-E and the always lower amounts of 2-MCPD-E varied significantly (Table 1).

The fish meat balls consisted of 50-60\% minced meat from one or more fish species, and were formed, breaded and fried. Two of them were intended for immediate consumption. One producer sold the meat balls unfried. Again, this led to very different fat contents of the products $(7.8-10 \%$ compared to $1.8 \%$ fat) with approximately the same salt content. In all fried meat balls the amount of 2-MCPD-E were below LOQ and contained only low amounts 3-MCPD-E (Table 1).

The fact that MCPD-E and G-E are formed during the pre-frying process is confirmed by the findings in the fish fingers and in the other breaded products that were offered unfried. In these products, the amounts of 2- and 3-MCPD$\mathrm{E}$ and G-E were below the LOQ. Therefore, the 2- and 3-MCPD-E contents of the unfried breaded products differ significantly $(p<0.05)$ from the contents in both pre-fried fish fingers and other breaded products.

When comparing the different pre-fried products (fish fingers, breaded fish fillets and squid rings) no significant differences $(p<0.05)$ were found for the respective MCPD-E and G-E contents. The contents of the contaminants varied widely within a product category. In addition, no correlation between the contents of $\mathrm{NaCl}$ or fat and the contents of MCPD-E or G-E was found. The large variability of MCPDE contents in the samples is presumably mainly due to the fact that the products were randomly purchased from the trade; the exact frying temperature, as well as the heating time and type of frying oil, were unknown. Both the raw materials (frying oils) and the mentioned process parameters of different manufacturers presumably lead to the different contamination. It has been demonstrated that these factors have a significant influence $(p<0.05)$ on the formation of MCPD-E during pre-frying [33].

The 3-MCPD-E contents were significantly higher than the 2-MCPD-E contents in all tested samples of this product category. This was confirmed by comprehensive frying experiments carried out within the context of a research project of Merkle et al. [33].

In the samples, G-E were mostly not quantifiable or only present in small quantities. This is probably based on the commonly used industrial pre-frying temperature $\left(180-200{ }^{\circ} \mathrm{C}\right)$ and the short frying time (20-40 s). Under these conditions no increased formation of G-E in the products is to be expected [34].

\section{Domestic cooking of fish fingers}

Prior to consumption, breaded and pre-fried frozen fish products like fish fingers must be finally prepared by a heating step, whose influence on the contaminants contents was investigated. For calculation of the daily intake, the contents of the contaminants in the ready-prepared food are important.

The domestic cooking procedures were largely performed according to the manufacturer's recommendations on the packaging. In all cases, the fish fingers finally turned golden brown. The contents of MCPD-E and G-E of the unheated and heated fish fingers as well as frying oils are listed in Table 2. As all fish fingers were already pre-fried in the factory, both MCPD-E and, with one exception, G-E could be detected in all three products before the cooking experiments. Since no free MCPD was expected in the samples, its determination has been omitted.

Since each product was heated with all common cooking methods in the household, the effect of the cooking method on the MCPD-E and G-E content in the fish fingers is deductible.

A prolongation of the heating period (21 min instead of $15 \mathrm{~min}$ ) led to a significantly higher weight loss in the hotair fryer compared to the oven. During baking, which took place without the addition of oil, the products mainly lost water. Considering this baking loss, the original contents of MCPD-E and G-E in the fish fingers remained largely unchanged.

During roasting/frying in a pan or a fryer, heat is transferred from the oil to the fish finger, water is evaporated and oil is absorbed from the product. We assumed that after each meal preparation, the consumer disposes the entire frying oil in the pan, while the frying fats are reused in a deep fryer for several times. Therefore, the frying experiments with the three products were carried out one after the other without changing the fat in the fryer, while the oil in the pan was renewed every time.

In two of the three fish samples roasted in a pan, the contents of MCPD-E decreased by $30-50 \%$; however, in one sample the content slightly increased. The decrease and increase of the MCPD-E amounts in the product and in the frying oil appear to be due to a fat exchange between both. In all three products, the G-E content increased from approximately $10 \mu \mathrm{g} / \mathrm{kg}$ to approximately $30 \mu \mathrm{g} / \mathrm{kg}$.

The two kinds of fat used in the fryer contained very different amounts of MCPD-E and G-E (Table 2). The vegetable fat, which contained palm oil, had the higher amounts. This was to be expected, as significantly higher MCPD-E and $\mathrm{G}-\mathrm{E}$ contents were already found in palm oil compared to other edible oils [8]. The G-E amounts in coconut and vegetable fat increased during the first frying, but did not increase further during the two following ones. In coconut fat, the 3-MCPD-E content showed a slight increase with each frying process, while it slightly decreased in the vegetable fat. The 2-MCPD-E contents changed only insignificantly in both fats. 
The weight loss during frying in a fryer was significantly lower in the vegetable fat than in the coconut fat despite the same frying temperature and frying time. All products fried in vegetable fat had higher contents of MCPD-E and $\mathrm{G}-\mathrm{E}$ than the products fried in coconut fat. This is due to the significantly higher contents of MCPD-E and G-E in the vegetable fat.

In summary, the MCPD-E and G-E contents in the baked fish fingers depend solely on the initial MCPD-E (and G-E) content of the pre-fried product. When frying, the MCPDE content in the ready-to-eat fish fingers can be reduced or significantly increased depending on the contamination of the frying oil used. However, due to the limited amount of experimental data, no final conclusion on the effect of cooking on the MCPD-E and G-E content in fish fingers can be drawn.

Some studies have already shown that the amounts of free and bound 3-MCPD increase during the preparation of food in the household. This influence was mainly observed during the toasting of bread [35-37] and grilling of cheese, fish or meat $[37,38]$. To the best of our knowledge, the data of comparable cooking experiments with fish fingers have not yet been published.

\section{Fried fish products}

In total, 40 different fried fish products from 22 manufacturers were examined. All products contained herring (Clupea harengus) as the raw material. Fried herring is offered as gutted fish without the head or in the form of fillets, bites, rolls or rollmops in a marinade containing vinegar, salt and onions as well as other seasoning ingredients. The fish content of these products must be at least 50\% [27]. Wheat flour, starch and salt were the main components of the breading. According to the list of ingredients, rapeseed oil was used as frying oil for all fried herring products. The majority of the products were offered in jars or plastic containers as ready-to-eat products with a short shelf-life and they have to be stored in the refrigerator. A total of 14 products were offered in cans as a pasteurised product.

The amounts of MCPD-E and G-E found in the fried products are summarised in Table 3. For more information on the individual samples see supplement Table S2. Since only the fried fish is consumed in the marinated products, only the fish was examined. Free MCPD content in these products was below LOQ.

The amounts of 2- and 3-MCPD-E in the analysed products varied widely with a median value of about 30 and $100 \mu \mathrm{g} / \mathrm{kg}$, respectively. However, the high contents of 602 and $808 \mu \mathrm{g} / \mathrm{kg} 3$-MCPD-E in the pasteurised and unpasteurised fried fish products were outliers.

The large variation of the MCPD-E contents in these samples was probably also caused by the fact that the products were bought randomly from the trade and the essential influencing factors such as the exact frying temperature, frying time and condition of the frying oil at the time of production were not known. It was also confirmed in previous frying experiments with breaded herring fillets that the heating period had a significant influence on the formation of MCPD-E during the frying process [39]. The amounts of G-E were below LOQ in half of the products. This can probably be attributed to the applied frying temperature $\left(170-180^{\circ} \mathrm{C}\right)$ and frying time [34].

No significant differences $(p<0.05)$ were found between pasteurised and unpasteurised fried fish products. This finding was also confirmed by previous experiments [39] and it is presumably based on the low pasteurisation temperature $\left(95-98{ }^{\circ} \mathrm{C}\right)$, which does not increase the formation of MCPD-E in pasteurised samples.

The amounts of 2- and 3-MCPD-E of these fried herring products are not significantly different $(p<0.05)$ from the amounts in the investigated fish fingers. However, they differ significantly from the amounts in unfried breaded products.

Although only a limited amount of published data is available, the amounts of 3-MCPD-E were similar to the amounts of $150-280 \mu \mathrm{g} / \mathrm{kg}$ in deep-fried fish reported by Chung [40] and $132 \pm 89 \mu \mathrm{g} / \mathrm{kg}$ in preserved marinated fried fish fillets investigated by Karl [24]. However, the mean amounts of the contaminants in this study were slightly higher than the data published by EFSA [8]. In this report, the mean values (middle bound) for the total 3-MCPD (42 $\mu \mathrm{g} / \mathrm{kg})$, total 2 -MCPD $(14 \mu \mathrm{g} / \mathrm{kg})$ and G-E $(30 \mu \mathrm{g} / \mathrm{kg})$ in fried or baked fish were specified.

A producer of fried fish products can find practical advice in the"Toolbox for the Mitigation of 3-MCPD-E and G-E in food" published by the German Federation for Food Law and Food Science [41] and the "Guidelines for the commercial or industrial production of (pre-)fried fish products" [42].

\section{Canned fish}

The term "canned fish" refers in particular to fish products in their own juice and/or marinade, vegetable oil, sauces or creams. The 45 investigated canned fish products were from 25 different producers. Among the samples, $60 \%$ were pickled in vegetable oil, $20 \%$ in water or marinade and the rest in sauces or creams.

The amounts of MCPD-E and G-E found in the canned products are summarised in Table 3. For more information on the individual samples see Table S3 in the supplement. Again, it is noticeable that the contents of MCPD$\mathrm{E}$ and $\mathrm{G}-\mathrm{E}$ within a product group can vary widely. This agrees with previously reported values for bound 3-MCPD (range $<5-230 \mu \mathrm{g} / \mathrm{kg}$ ) in canned fish by Chung et al. [40]. From the tested market samples, those in sunflower oil 
contained the highest mean amounts of 3-MCPD-E. With a few exceptions, the amounts of 2-MCPD-E were very low (range $<$ LOQ- approx. $70 \mu \mathrm{g} / \mathrm{kg}$ ).

Overall, no significant differences $(p<0.05)$ between the MCPD-E amounts in fish fingers, other breaded and frozen pre-fried fish products and fried fish products were identified. However, a significantly lower $(p<0.05) 2$-MCPD-E and 3-MCPD-E content was analysed in canned fish. This is probably due to the fact that the production of canned fish not necessarily involves a thermal treatment (frying) of the fish products.

\section{Smoked fish products}

The 82 smoked fish products from 31 different manufacturers included all fish species normally used for cold or hot smoking. According to the information on the packaging, mostly beech but also alder, juniper, "domestic wood" or "precious wood" were used for the generation of smoke. The type of wood affects the colour, smell and taste of the smoked product.

The studied smoked fish products are listed in Table 4 . According to the information on the product or statements in the shops or on the Internet, the majority of the products could be assigned to a certain type of smoke generation, but this was not possible in the case of the as "unknown" labelled samples. Most smoked fish products of the German market are manufactured in modern smoking kilns. However, because traditionally smoked fish are often more prone to increased MCPD contents, these products were preferably investigated in this study.

The 31 canned smoked fish products from eleven producers contained mainly smoked herring, salmon, mackerel or sprats, which were supplied in a mixture of their own juice with vegetable oil, only vegetable oil or tomato cream and as fish cream. According to the declaration on the package, only beech was used for smoking. However, the type of smoke generation is unknown. The amounts of free MCPD, MCPD-E and G-E in the studied smoked fish products are listed in detail in Table 5. A list of the contents in the individual samples can be found in the supplement,
Table S4. The majority of the smoked fish products were hot smoked. The cold-smoking process is primarily used for whole salmon fillets, which then are usually sliced before they are sold on the market.

Smoked fish products mainly contain free 3-MCPD. Smoke generation is associated with the thermal fission of polysaccharides (like cellulose) to form C3-fragments such as hydroxyacetone that can react with hydrochloric acid to form 3-MCPD [1]. The smoke absorption depends on the smoke density, the duration of the smoke treatment and the surface quality (dry, moist, salty or greasy) of the food [29].

The median contents of free 3-MCPD in the edible part of the market samples sorted by fish species are shown in Fig. 1.

The highest amounts were measured in eels, Schillerlocken (hot- smoked stripes of belly walls from dogfish) and sprats. The smoked eels and smoked sprats were exclusively from Altona kilns. In the case of trout and mackerel, products smoked in Altona kilns contained the highest contents of MCPD.

Hot-smoked fish from traditional kilns (Altona Ofen) contained the highest median value of approximately $50 \mu \mathrm{g}$ free $3-\mathrm{MCPD} / \mathrm{kg}$. The amounts varied widely between 10 and $250 \mu \mathrm{g} / \mathrm{kg}$. The results are consistent with data already published for traditionally smoked fish by Karl [24]. The significantly lower concentrations in cold-smoked products from Altona kilns are probably because, in these cases, the smoke was formed externally and then discharged into the smoking chamber. Hot- smoked products from Altona kilns showed usually higher MCPD contents than products smoked with smouldering or friction smoke in modern smoking kilns (Table 5).

The amounts of free 2-MCPD were below the limit of quantification of $10 \mu \mathrm{g} / \mathrm{kg}$ edible portion in all investigated smoked products. Apart from one sample, this also applied to the amounts of 2-MCPD-E (LOQ: $20 \mu \mathrm{g} / \mathrm{kg}$ ). In only approximately $10 \%$ of the samples 3 -MCPD-E could be quantified. The amounts of G-E ranged between $<$ LOQ and $119 \mu \mathrm{g} / \mathrm{kg}$.

For the reduction of PAH amounts, the use of an external smoke generator has already been recommended [43]. From

Table 4 Investigated smoked fish products separated by type of smoke generator

\begin{tabular}{ll}
\hline Smoke generator & Basket samples \\
\hline "Altonaer Ofen" & $\begin{array}{l}\text { Carp (pieces), eel (whole, stremel), escolar, black halibut (pieces), mackerel (unfolded gutted fish), salmon (curls, stremel, } \\
\text { sliced fillet), sprats (whole), sturgeon (stremel), trout (whole, fillet) }\end{array}$ \\
Smouldering smoke & $\begin{array}{l}\text { Black halibut (pieces from the middle and the tail), brook trout (fillet), escolar, herring (rollmops, bückling), mackerel } \\
\text { (whole, fillet), salmon (sliced fillet, rolled up in a spiral), shrimp }\end{array}$ \\
$\begin{array}{l}\text { Friction smoke } \\
\text { Liquid smoke }\end{array}$ & $\begin{array}{l}\text { Black halibut (cube, fillet cut), cod (fillet), salmon (sliced, fillet cut), tuna (fillet) } \\
\text { Unknown }\end{array}$ \\
$\begin{array}{l}\text { Black halibut (pieces), dogfish (Schillerlocken), mackerel (fillet), salmon (sliced fillet, stremel), sprats (whole), trout } \\
\text { (whole, fillet) }\end{array}$
\end{tabular}




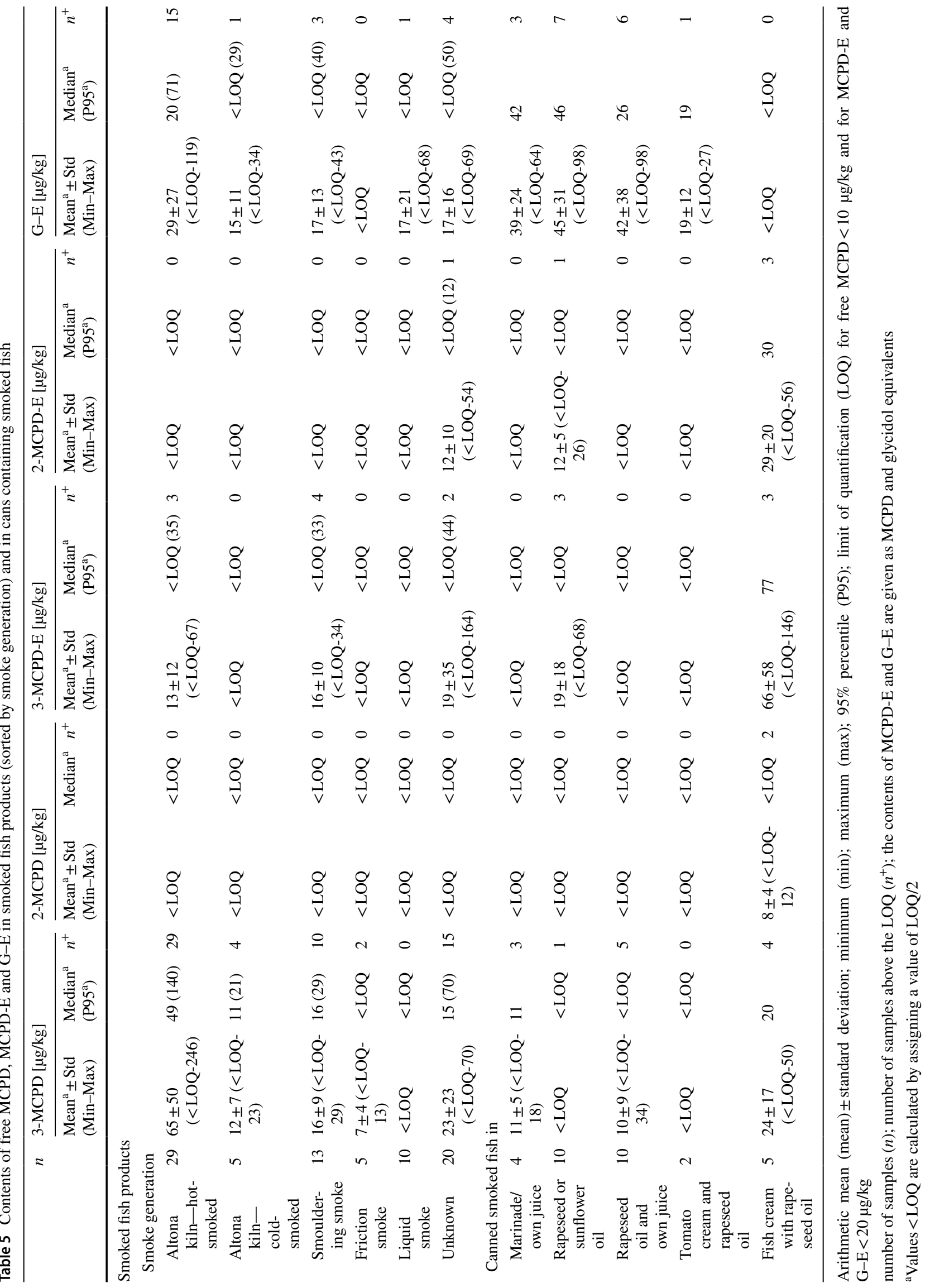




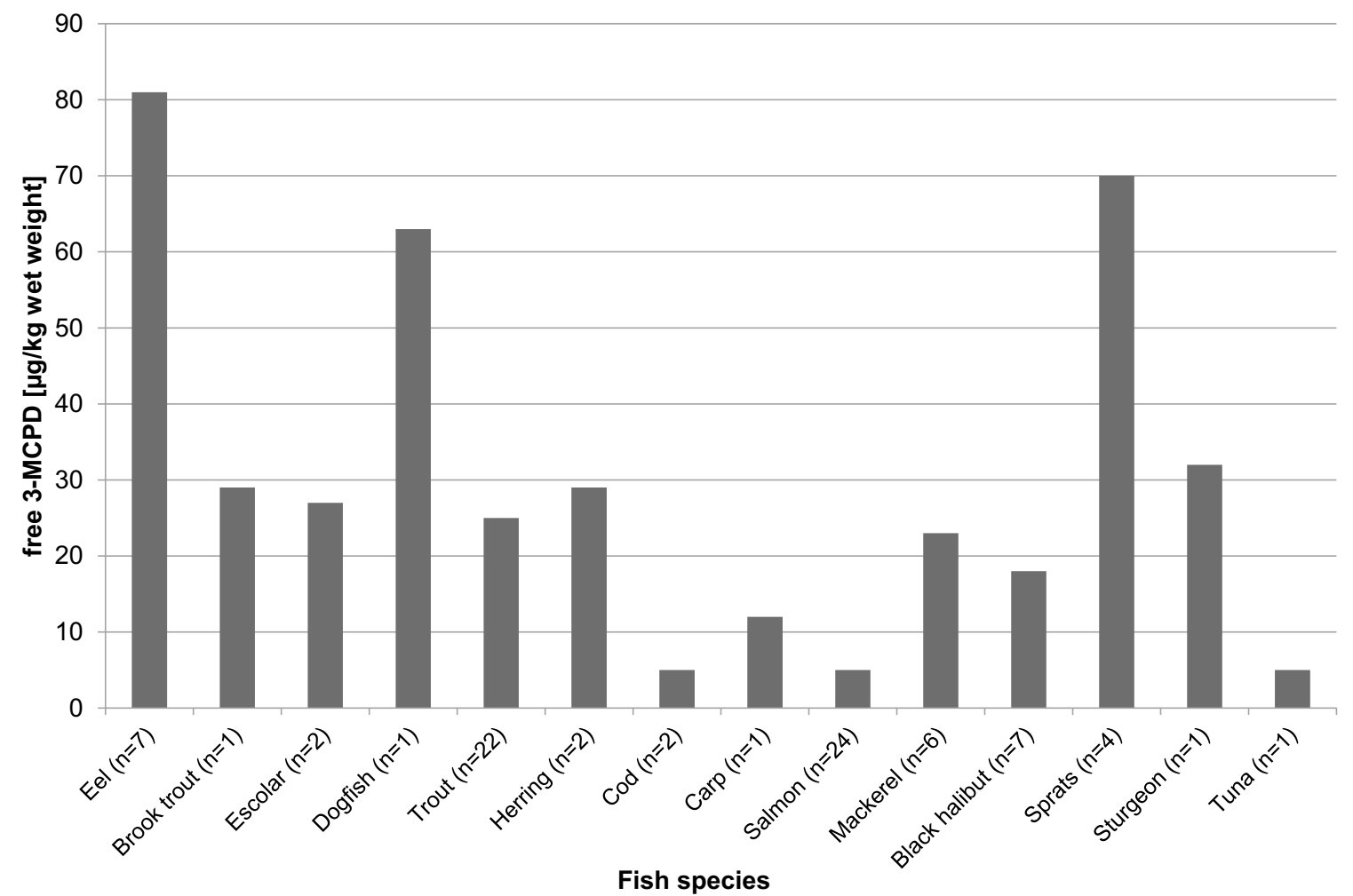

Fig. 1 Free 3-MCPD (median, medium bound) in smoked fish samples sorted by fish species ( $n$ number of fish samples)

the results of this study, it can be deduced that an external smoke generator is also preferable to the direct generation of smoke in order to reduce the amounts of 3-MCPD in the smoked products. The contents of the products smoked in modern kilns agreed well with the medium bound values reported by the Federal German Institute for Risk Assessment (BfR) (mean: $29 \mu \mathrm{g}$ 3-MCPD/kg; median: $20 \mu \mathrm{g}$ 3-MCPD/kg; [22]) and by EFSA (total 3-MCPD mean: $18 \mu \mathrm{g} / \mathrm{kg}$; total 2-MCPD mean: $6.1 \mu \mathrm{g} / \mathrm{kg}$; G-E mean: $5.8 \mu \mathrm{g} / \mathrm{kg}$; [8]).

In the products manufactured with liquid smoke, the MCPD contents were below the limit of quantification. However, these products were purchased only from one manufacturer. The liquid smoke used in the production of the tested market samples was also analysed. The product contained approximately $1000 \mu \mathrm{g} 3-\mathrm{MCPD} / \mathrm{kg}$. Free $2-\mathrm{MCPD}$ was not detectable. This is in accordance with data previously reported by Kuntzer and Weißhaar, who already reported high amounts (200-760 $\mu \mathrm{g} / \mathrm{kg})$ of 3-MCPD in six commercially available liquid smoke flavourings [1]. The liquid smoke was thus not free from 3-MCPD. If one considers, however, that approximately $50 \mathrm{ml}$ of liquid smoke is sufficient for cold smoking of $100 \mathrm{~kg}$ salmon fillets, this might explain why in these smoked fish the contents of 3-MCPD were always under the quantification limit $(<10 \mu \mathrm{g} / \mathrm{kg})$.
Amounts of free 3-MCPD found in cans with smoked fish were very low (Table 5 and S5). The amounts of free 2-MCPD were only slightly above the LOQ in two samples. The MCPD-E and G-E analysed in the cans may also originate from the added edible oil.

\section{Smoked spice preparations}

All spice preparations differed in their composition. Most samples contained either smoked salt (36\% of the samples) or smoked paprika (36\% of the samples). In two samples, the smoke could not be directly assigned to any ingredient. Smoke flavours were added to all barbecue sauces, which are based on tomato paste.

With one exception, free 3-MCPD could be determined in all solid spice preparations (Table 6). The contents of free 2-MCPD, MCPD-E and G-E were always below the LOQ. The spice preparation with the highest 3-MCPD content $(146 \mu \mathrm{g} / \mathrm{kg})$ contained smoked sucrose. In one sample, the content of free 3-MCPD could originate from the smoked paprika as well as the added soy sauce powder. As only small quantities are used for the preparation of food, the dietary uptake of MCPD via these spices is very low. 
Table 6 Contents of free 2- and 3-MCPD in spice preparations with a smoked ingredient

\begin{tabular}{llll}
\hline Product & $n / n^{+}$ & $\begin{array}{l}\text { 3-MCPD [ } \mu g / \mathrm{kg}] \\
\text { Median (Min-Max) }\end{array}$ & 2-MCPD $[\mu \mathrm{g} / \mathrm{kg}]$ \\
\hline $\begin{array}{l}\text { Solid spice prepara- } \\
\text { tion }\end{array}$ & $11 / 10$ & $52(<\mathrm{LOQ}-146)$ & $<\mathrm{LOQ}$ \\
$\begin{array}{l}\text { Barbecue sauce } \\
\text { a }\end{array}$ & $3 / 1$ & $<\mathrm{LOQ}-14$ & $<\mathrm{LOQ}$ \\
\hline
\end{tabular}

minimum (Min); maximum (Max); limit of quantification (LOQ) for MCPD $<10 \mu \mathrm{g} / \mathrm{kg} ; n$ number of samples; $n^{+}$number of samples with 3-MCPD above the LOQ

\section{Conclusion}

This study provides a comprehensive overview of MCPD contents in various processed fishery products commonly consumed in Germany. In general, the results show that the MCPD (smoked fishery products), MCPD-E and G-E contents (breaded and pre-fried, frozen and fried fish products and canned fish products) can vary greatly within the same product category, which indicates that their amounts depend strongly on the applied process conditions. This study shows, that the thermal treatment is a processing prerequisite for the formation of the MCPD-E in breaded and pre-fried frozen fish products and fried fish products. Therefore, it is suggested to the fish processing industry to incorporate the $\mathrm{MCPD} / \mathrm{G}-\mathrm{E}$ topic into the quality assurance programs and to monitor the actual contents of MCPD, MCPD-E or G-E of the products. Another aspect of the dietary uptake of MCPD/G-E is the domestic preparation of these products.

Supplementary Information The online version contains supplementary material available at https://doi.org/10.1007/s00217-021-03746-6.

Acknowledgements The authors thank the Federal Association of the German Fish Processing Industry and Fish Wholesalers e.V. and the Association of Oilseed-Processing Industries in Germany (OVID) for the financial support of the FEI project. Furthermore, we wish to thank SGS Germany GmbH, especially Dr. Jan Kuhlmann, for providing technical equipment for analysing MCPD-E and G-E contents. The authors are thankful to Iris Bagge and Kai-Uwe Scholibo (Max Rubner-Institut Hamburg) for their technical assistance.

Funding Open Access funding enabled and organized by Projekt DEAL. This research (Project AiF 18577N) was funded by the German Federal Ministry of Economics and Energy (via AiF) and the FEI (Research Association of the German Food Industry, registered association, Bonn), http://www.fei-bonn.de/gefoerderte-projekte/proje ktdatenbank/aif-18577-n.projekt.

\section{Declarations}

Conflict of interest The authors declare no conflict of interest.
Human and animal rights This article does not contain any study with human or animal objects.

Open Access This article is licensed under a Creative Commons Attribution 4.0 International License, which permits use, sharing, adaptation, distribution and reproduction in any medium or format, as long as you give appropriate credit to the original author(s) and the source, provide a link to the Creative Commons licence, and indicate if changes were made. The images or other third party material in this article are included in the article's Creative Commons licence, unless indicated otherwise in a credit line to the material. If material is not included in the article's Creative Commons licence and your intended use is not permitted by statutory regulation or exceeds the permitted use, you will need to obtain permission directly from the copyright holder. To view a copy of this licence, visit http://creativecommons.org/licenses/by/4.0/.

\section{References}

1. Kuntzer J, Weißhaar R (2006) The smoking process-a potent source of 3-chloropropane-1,2-diol (3-MCPD) in meat products. Deut Lebensm-Rundsch 102:397-400

2. Crews C, Hasnip S, Chapman S, Hough P, Potter N, Todd J, Matthews W (2003) Survey of chloropropanols in soy sauces and related products purchased in the UK in 2000 and 2002. Food Addit Contam 20:916-922

3. Beekman JK, Granvogl M, Macmahon S (2020) 2- and 3-Monochloropropanediol (MCPD) esters and glycidyl esters: methods of analysis, occurrence, and mitigation in refined oils, infant formula, and other processed foods. In: Birch CS, Bonwick GA (eds) Mitigation contamination from food processing, chapter 4, pp 75-107

4. IARC (2012) 3-Monochloro-1,2-propanediol. Some chemicals present in industrial and consumer products, food and drinking water. IARC Monographs 101:349-374

5. Abraham K, Appel KE, Berger-Preiss E, Apel E, Gerling S, Mielke H, Lampen A (2013) Relative oral bioavailability of 3-MCPD from 3-MCPD fatty acid esters in rats. Arch Toxicol 87:649-659

6. EFSA (2018) Update of the risk assessment on 3-monochloropropane diol and its fatty acid esters. EFSA J 16(1):5083

7. JECFA World Health Organization \& Joint FAO/WHO Expert Committee on Food Additives (83rd, 2017: Geneva, Switzerland) (2017) Evaluation of certain contaminants in food: eighty-third report of the Joint FAO/WHO Expert Committee on Food Additives. In: WHO Technical Report Series; 1002 World Health Organization, pp 90-106 (Chapter 3.5: 3-MCPD esters and 3-MCPD)

8. EFSA (2016) Risks for human health related to the presence of 3- and 2-monochloropropanediol (MCPD), and their fatty acid esters, and glycidyl fatty acid esters in food. EFSA J 14(5):4426

9. Buhrke T, Frenzel F, Kuhlmann J, Lampen A (2015) 2-Chloro1,3-propanediol (2-MCPD) and its fatty acids: cytotoxicity, metabolism, and transport by human intestinal Caco- 2 cells. Arch Toxicol 89:2243-2251

10. Appel KE, Abraham K, Berger-Preiss E, Hansen T (2013) Relative oral bioavailability of glycidol from glycidyl fatty acid esters in rats. Arch Toxicol 87:1649-1659

11. IARC (2000) IARC monographs on the evaluation of carcinogenic risks to humans, some industrial chemicals. IARC Monograph 77:469-486

12. Commission E (2006) Commission Regulation (EC) No $1881 / 2006$ of 19 December 2006 setting maximum levels for certain contaminants in foodstuffs. Off J Eur Union L 364:5-24 
13. Commission E (2018) Commission Regulation (EU) 2018/290 of 26 February 2018 amending Regulation (EC) No 1881/2006 as regards maximum levels of glycidyl fatty acid esters in vegetable oils and fats, infant formula, follow-on formula and foods for special medical purposes intended for infants and young children. Off J Eur Union L 55:27-29

14. Commission E (2020) Commission Regulation (EU) 2020/1322 of 23 September 2020 amending Regulation (EC) No 1881/2006 as regards maximum levels of 3-monochloropropanediol (3-MCPD), 3-MCPD fatty acid esters and glycidyl fatty acid esters in certain foods. Off J Eur Union L 310:2-5

15. Council Regulation (EEC) (1993) No 315/93 of 8 February 1993 laying down Community procedures for contaminants in food. Off J Eur Commun L 37:1-5

16. Kuhlmann J (2011) Determination of bound 2,3-epoxy-1-propanol (glycidol) and bound monochloropropanediol (MCPD) in refined oils. Eur J Lipid Sci Tech 113:335-344

17. Gao B, Li Y, Huang G, Yu L (2019) Fatty acid esters of 3-monochloropropanediol: a review. Annu Rev Food Sci Tech 10:259-284

18. Bognár E (2017) Occurrence of chloropropanols and glycidol esters in foods-a literature review. J Food Investig 63:1506-1517

19. Reece P, Crews C, Hasnip S, Hamlet C, Sadd P, Baxter D, Doležal $M(2005)$ The origin and formation of 3-MCPD in foods and food ingredients. In: FSA Project C03017-19

20. Samaras VG, Giri A, Zelinkova Z, Karasek L, Buttinger G, Wenzl $\mathrm{T}$ (2016) Analytical method for the trace determination of esterified 3- and 2-monochloropropanediol and glycidyl fatty acid esters in various food matrices. J Chromatogr A 1466:136-147

21. Crews C, Hough P, Brereton P, Harvey D, Macarthur R, Matthews W (2002) Survey of 3- monochloropropane-1,2-diol (3-MCPD) in selected food groups, 1999-2000. Food Addit Contam A 19:22-27

22. BfR (2012) 3-MCPD-Fettsäureester in Lebensmitteln: Stellungnahme Nr. 006/2013 des BfR vom 3

23. EFSA (2013) Analysis of occurrence of 3-monochloropropane1,2-diol (3-MCPD) in food in Europe in the years 2009-2011 and preliminary exposure assessment. EFSA J 11(9):3381

24. Karl H, Merkle S, Kuhlmann J, Fritsche J (2016) Development of analytical methods for the determination of free and ester bound 2-, 3- MCPD, and esterified glycidol in fishery products. Eur J Lipid Sci Technol 118:406-417

25. Commission E (2014) Commission Recommendation of 10 September 2014 on the monitoring of the presence of 2 and 3-monochloropropane-1,2-diol (2 and 3- MCPD), 2- and 3-MCPD fatty acid esters and glycidyl fatty acid esters in food. Off J Eur Union L 271:93-95

26. FIZ (Fisch-Informationszentrum) (2020) Fisch Wirtschaft. Daten und Fakten 2020. https://www.fischinfo.de/index.php/markt/daten fakten. Accessed 17 Dec 2020

27. BMEL (Bundesministerium für Ernährung und Landwirtschaft) (2011) Leitsätze für Fische, Krebs- und Weichtiere und Erzeugnisse daraus. https://www.bmel.de/SharedDocs/Downl oads/DE/_Ernaehrung/Lebensmittel-Kennzeichnung/Leitsaetze Fische.pdf?_blob=publicationFile\&v=2. Accessed 2 Sep 2020

28. Krüger KE (2004) Fisch. In: Heiss R (ed) Fisch. Biotechnologische, chemische, mechanische und thermische Verfahren der Lebensmittelverarbeitung. 6. Aufl. Springer, Berlin, Heidelberg, New York

29. Tülsner M, Koch M (2010) Technologie der fischverarbeitung. Behr's Verlag GmbH \& Co, Hamburg
30. European Commission (2013) Commission implementation of the regulation 1321/2013 establishing the union list of authorised smoke flavouring primary products for use in or on foods and /or for the preparation of derived smoke flavourings. Off J Eur Union L 333:54-67

31. ÖKOTEST (2012) Stäbchenprobe. Heft 10:82-86

32. ÖKOTEST (2020) Fischstäbchen. Heft 7. https://www.oekotest. de/essen-trinken/Fischstaebchen-im-Test-Knapp-ein-Drittel-mitFettschadstoffen-belastet_11330_1.html. Accessed 2 Sep 2020

33. Merkle S, Ostermeyer U, Rohn S, Karl H, Fritsche J (2018) Mitigation strategies for ester bound 2-/3-MCPD and esterified glycidol in pre-fried breaded and frozen fish products. Food Chem 245:196-204

34. Pudel F, Benecke P, Fehling P, Freudenstein A, Matthaus B, Schwaf A (2011) On the necessity of edible oil refining and possible sources of 3-MCPD and glycidyl esters. Eur J Lipid Sci Technol 113:368-373

35. Breitling-Utzmann CM, Koebler H, Herbolzheimer D, Maier A (2003) 3-MCPD-occurrence in bread crust and various food groups as well as formation in toast. Deut Lebensm-Rundsch 99:280-285

36. Breitling-Utzmann CM, Hrenn H, Haase NU, Unbehend GM (2005) Influence of dough ingredients on 3-chloropropane1,2-diol (3-MCPD) formation in toast. Food Addit Contam 22:97-103

37. Crews C, Brereton P, Davies A (2001) The effects of domestic cooking on the levels of 3-monochloropropanediol in foods. Food Addit Contam 18:271-280

38. Inagaki R, Ito F, Shimamura Y, Masuda S (2019) Effect of chloride on the formation of 3-MCPD fatty acid diesters and glycidol fatty acid esters in fish, meats and acylglycerols during heating. Food Addit Contam A 36:236-243. https://doi.org/10.1080/19440 049.2018.1562231

39. Merkle S, Ostermeyer U, Rohn S, Karl H, Fritsche J (2018) Formation of ester bound 2- and 3-MCPD and esterified glycidol in deep-fried and pickled herring products. Eur J Lipid Sci Technol 120:1700464

40. Chung SWC, Chan BTP, Chung HY, Xiao Y, Ho YY (2013) Occurrence of bound 3-monochloropropan-1,2-diol content in commonly consumed foods in Hong Kong analysed by enzymatic hydrolysis and GC-MS detection. Food Addit Contam A 30:1248-1254

41. Bund für Lebensmittelrecht und Lebensmittelkunde e.V. (BLL) (2016) Toolbox for the Mitigation of 3-MCPD Esters and Glycidyl Esters in Food. https://www.google.com/search?client=firefox-b$\mathrm{e} \& \mathrm{q}=$ Toolbox + for + the + Mitigation + of $+3-\mathrm{MCPD}-\mathrm{E}+$ and $+\mathrm{G}-\mathrm{E}+$ in+food\%E2\%80\%9D. Accessed 7 Sep 2020

42. Ostermeyer U, Merkel S (2019) 3-MCPD Praxisleitfäden; Handbuch Fisch, Krebs- und Weichtiere; Behr`s Verlag 62. Aktualisierung Mai 2019

43. Codex Alimentarius Commission (2009) CAC/RCP 68. In: Code of practice for the reduction of contamination of food with polycyclic aromatic hydrocarbons (PAH) from smoking and direct drying processes

Publisher's Note Springer Nature remains neutral with regard to jurisdictional claims in published maps and institutional affiliations. 